\title{
INFORMATION AND COMMUNICATION TECHNOLOGY FOR SUSTAINABLE DEVELOPMENT
}

\author{
Yogesh Punia \\ Junior Research Fellow, Dept. of Education, KUK
}

Voice of Research

Volume 5, Issue 1

June 2016

ISSN $2277-7733$

\begin{abstract}
Information and communication technology (ICT) stands for the combined set of resources, whether physical, infrastructure or human, that stands for the efficient transformation of information across the globes. In the recent years, we have witnessed several changes in the global scenario as the rapidly boundaries caused the people, society and nations to merge together for a common cause of development. The spread of information and communication technology and global interconnectedness has great potential to accelerate buman progress to bridge the digital divide and develop knowledge societies. Sustainable development is required for maintaining proper balance between the exhausting resources and our existence. This paper is an attempt to explore the various aspects of ICT, the challenges in its implementation and future prospects of ICT in our vision of world as a better place - to live and to prosper.
\end{abstract}

Keywords: ICT and Sustainable Development

ICT have a major impact on economy and social relationship among individual, community and nation. It has a major role in globalization of capital, labour, product market and is responsible for covering the distance among individual over the globe. ICT is used as a tool for development used in all spheres.ICT is much more than a computer and used in commercial, industrial and social systems. It's a fundamental part of economic growth.

Sustainable development is not merely concerned with environment and development but it is related to all round development in every aspect. This usually comprises of three elements and these are also termed as pillars of sustainable development i.e.

i. Economic development: remove poverty, economic welfare, ii. Social development: improve the quality of education, housing, iii. Environment development: reduction of pollution and protect other environment sources.

ICT can be divided in two broad categories, the first are those who largely dependent on telecommunications that enables on demand communication like, e-commerce and egovernance. Second group of ICT applications can be called human independent. And it is necessary to have a interaction in all the three elements of sustainable development and technology make it possible. ICT helps in interaction between all these elements.

\section{Objectives}

1. To explore various dimensions of ICT; 2 . To define the success of ICT for sustainable development; 3 . To discuss various challenges and their respective measure to overcome.

\section{Research design}

This study is exploratory in nature and is an attempt to look into the various dimensions of ICT, Sustainable development and then for possible participative and collaboration measures that are needed for a positive impact.

1. Various dimensions of ICT: The 4C's of ICT are the main dimensions of it, namely computing, connectivity, content, capacity (human). These are as mentioned below:-

a) Computing: ICT is more than computers and for sustainable development it requires a lot of innovations in hardware and software. Computers and others devices should be affordable and easy to use with inference to local languages.

b) Connectivity: Developing countries especially rural areas are still remain without connectivity. Universe access requires new networking. ICT is more than connecting to internet- human development requires integration of all forms of ICT and Medias such as TV, radio etc.

c) Content: ICT will be relevant to sustainable development when it provides relevant content to the end-users. There should be appropriate efforts to make locally specific content. ICT will help in sustainable development only if it provides suitable content.

d) Capacity (human): Most people lack awareness of potential of ICT, they have no knowledge regarding its uses and benefits. There are not only technical barriers but also barriers related to social cultural and economical. The first goal of the government to increase literacy among its population.

e) Success of ICT for sustainable development: Success of ICT for sustainable development requires integration, scalability and sustainability.

a) Integration: ICT can't directly achieve millennium development goals rather it need to be integrated with development as well as societal process.ict can only help in achieving development as it's a mean not an end. While ICT is

40 | Voice of Research, Vol. 5 Issue 1, June 2016, ISSN 2277-7733 
concerned with sustainable development then it must be undertaken in global inclusiveness.

b) Scalability: The challenges of development are vast in area that it can't be solved by a single individual or group of people rather it requires collaboration and sharing experiences and scaling it to the mass for its betterment. All the stakeholders and end users have equal right to give their participation in assessing its needs, responsibilities and measures of success etc.

c) Sustainability: ICT for sustainable development must be economical sufficient and provide values to the end-users. ICT for sustainable development can only be sustainable if it provides values to the end users.

d) Various challenges and their measures to overcome: There are several issue that creates problem in achieving sustainable development through ICT. The challenges for ICT in sustainable development are divided in 4A's such as:-

a) Awareness: Due to illiteracy may of the people have no knowledge regarding uses and benefits of ICT. They don't even know what can be done with ICT

b) Availability: Appropriate hardware and software are not available many times that requires in fulfilling the needs of situation. Especially in rural areas there are less chances of availability of computers also.

c) Accessibility: Accessibility related to the ability of using the ICT. There are many e-learning programmes available on internet to obtain sustainable development. Most of the population doesn't have any idea that how to access such elearning courses.

d) Affordability: all the ICT usage including hardware, software cost it become too costly, sometimes it is beyond the range or common people. The system software or ICT appliances are sometimes beyond the average income or common people.

(II) There are some measures to overcome such barriers:- To overcome such barriers one has to pay attention towards the various dimensions of ICT i.e. 4C's of ICT. Measures to overcome such barriers in 4C's are:-

a) Computing: Computers are expensive for most people and are difficult to use. Even most of the experts spend a lot of time on their machines to upgrades them and regarding their security, so there must be a complementary technology like: mobile phones.

b) Connectivity: To have a worldwide access with technology it is essential to have connectivity on large scale even in rural areas. In most of the developing countries the rural areas are beyond the connectivity or it may be expensive.

c) Content: Meaningful content should be available for the end users. Because sometimes the content is available but it is beyond the range or local languages. In addition rich content demands multimedia and that result in broad based connectivity.

d) Capacity (human): Users need to be aware, literate and well aware about the uses of ICT. They also have the power to use the ICT in best way to utilize its benefits with integration with society and economy.

\section{Conclusion}

Development has been our major aim right from the inception of life on this planet and we have travelled great heights and lows in order to be where we are today. ICT has done a tremendous and commendable job in bridging up the physical boundaries and it is therefore, one of the major transformation parameters. Although, we should not target that life should be seen in qualitative terms and so should be in development. Sustainable development has been the focal point since the start of this decade and should be dealt with immediate priority. For making our world a better, we could make it a constitution and we take adequate steps soon. Nature has always helped us to prosper and it's our time to pay our dues.

\section{Bibliography}

Albu, M. \& Scott, A. (2001). Understanding Livelihoods that involve micro-enterprise: Markets and Technological Capabilities in the SL Framework. Bourton, UK. Intermediate Technology Development Group.

Avital, M., Lyytinen, K., King, J. L., Gordon, M. D., GrangerHapp, E., Mason, R. O., \& Watson, R. T. (2007). Leveraging Information Technology to Support Agents of World Benefit. Communications of the AIS (19), pp. 567-588.

Birkeland, J. (2002). Design for Sustainability: A Sourcebook of Integrated, Eco-Logical Solutions. London: Earthscan Publications.

Chapman, R.T. Slaymaker, and Young, J. (2001). Livelihoods Approaches to Information and Communication in support of Poverty Elimination and Food Security. Overseas Development Institute. London.

Glenn, J. C., and Gordon, T. J. (1998). State of the Future: Issues and Opportunities. The Millennium Project, American Council for the United Nations University, Washington, DC. 


\title{
FACTORS INFLUENCING GOLD PRICES
}

\section{Renisha Chainani}

Sr. Manager - Research, Edelweiss Financial Services Ltd.
Voice of Research

Volume 5, Issue 1

June 2016

\begin{abstract}
ISSN $2277-7733$
Abstract

Gold is a finite source and when global economic conditions make gold more attractive, gold demand increases, making the price of gold rise. It is used as a standard of value for currencies all over the world. Gold Price is impacted by production costs, money supply, comfort or discomfort with financial or geopolitical stability, the demand generated by jewelry and industry, value of various currencies and actions taken by central banks. Gold can also be used as hedge against inflation and diversifying tool in hard times.
\end{abstract}

Keywords: Gold, Safe-Heaven, Investment, Jewelry, Bullion, Interest Rate, Monetary Easing, Monetary Tightening, Crisis, Geopolitical Tensions, ETF, FED, Correlation.

Archeologists claim that people have been mining and coveting Gold for at least 5,000 years, and this precious metal is likely to remain precious even if the price fluctuates often. If you plan to buy gold, you need to understand that the price is impacted by production costs, money supply, comfort or discomfort with financial or geopolitical stability, the demand generated by jewelry and industry, and actions taken by central banks. In other words, gold is a finite resource and when global economic conditions make gold more attractive, gold demand increases, making the price of gold rise. But the actual value of gold remains fairly stable in the long run, and the price could simply reflect temporary uncertainty or simple currency fluctuation.

Below are seven significant influences on gold price fluctuations that any investor with an interest in gold trading should understand.

\section{Supply and Demand}

Like most commodities, the basic principles of supply and demand play a major role in determining the price of gold. However, due to the physical limitations of mining for gold, the supply of gold in the world remains relatively stable (with the addition of the small amounts that are mined every year). This means that demand has a much larger impact on gold prices than supply does. When gold consumption increases, so does the price; the only thing that will drive prices down in a significant way is a decrease in demand.

\section{Supply}

Only about 2,500 metric tons of gold get produced each year, compared to an estimated 165,000 metric tons in the entire world's gold supply. To visualize this, imagine all of the gold in the world filling up three-and-a-half Olympic-sized swimming pools, and this year's production forming a cube that is only about 16 square feet.

Even though new production might seem modest compared to the total supply, production costs can influence the cost of all gold in the world. When production costs rise, miners sell gold for more money to preserve their profits, and those higher costs also get reflected when it comes time to sell coins if they were minted from gold that was originally mined yesterday or thousands of years ago.

China is the largest producer of gold in the world, accounting for about $15 \%$ of total gold production. Asia, as a whole, produces about $22 \%$ of newly mined gold, Central and South America produce around 17\%, and North America supplies around 15\%. Africa and the CIS (Commonwealth of Independent States) contribute $20 \%$ and $14 \%$, respectively, to gold production.

\section{Demand}

Safe-haven Demand: Gold is typically considered a safe haven when currency markets are volatile. United States Treasury Bills are also considered a safe haven even in a tumultuous economic climate because they are backed by the full faith and credit of the U.S. government. Increasing gold prices are a traditional indicator of a recession or a downturn in an economy. People run to the safety of gold when they think the value of other investments may go down in the future.

People flock to gold when the current paper money system experiences uncertainty. Some investors prefer the physical and tangible security of holding gold when central banks are going through deficits as a protection of wealth. In turn, an increased demand drives up the value of gold even more

Investment Demand: Gold ETF demand inflows Jan to April rose $24 \%$ from the end of 2015 as the gold price gained $20 \%$ and the Bloomberg Dollar Spot Index fell 4\%. This suggests the 34\% gold-price decline from the $\$ 1921$ (2011 peak) is luring back longer-term investors seeking a safe haven.

\section{Gold ETF Demand and Gold Price}

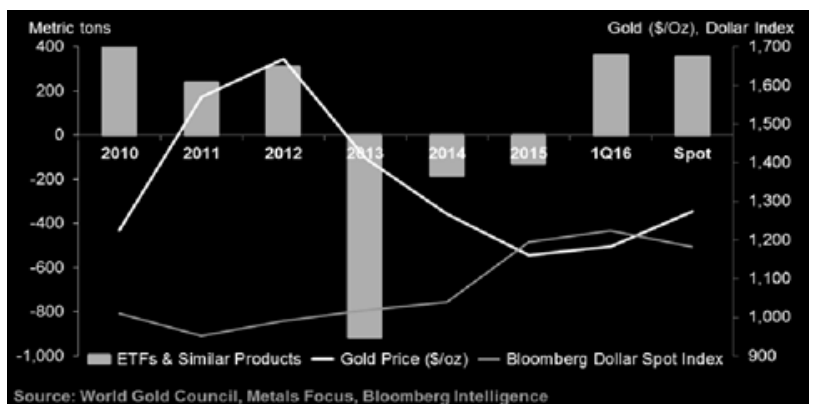

Physical Demand from Consuming Nations: India and China are the world's two largest consumers of gold, and together they make up about $50 \%$ of gold's global demand. Gold is treated more as a commodity in these two countries, and its demand is relatively inelastic. Even gold's near 9\% surge in price since the beginning of 2016 hasn't curbed its appeal. Instead, buying seems to have picked up. 